\title{
Habitat complexity and coral reef fish diversity and abundance on Red Sea fringing reefs
}

\author{
Callum M. Roberts ${ }^{1}{ }^{\bullet}$, Rupert F. G. Ormond ${ }^{2}$ \\ ${ }^{1}$ Marine Biology Section, Faculty of Science, Suez Canal University, Ismailia, Egypt \\ ${ }^{2}$ Tropical Marine Research Unit, Department of Biology, University of York, York Y01 5DD, United Kingdom
}

\begin{abstract}
The influence of several substratum variables, particularly structural complexity and live coral cover, on coral reef fish species richness and abundance was investigated. By surveying fish species with varying strengths of association with the substratum and at different sampling scales, this study aims to assess the scale-dependence of correlations between substratum characteristics and fish community parameters. Fish from 5 families (Acanthuridae, Chaetodontidae, Labridae, Pomacentridae and Scaridae) were counted along transects by visual census. Substratum characteristics were measured from stereophotographic transects. Three measures of structural complexity were used: (1) an index of surface area, (2) the variety of different substrata (biological diversity), and (3) numbers of holes (of different sizes). Although the depth of peak species richness varied between families, overall there was a trend of increasing species richness with increasing depth. Surface index was a poor predictor of overall species richness but was significantly correlated with pomacentrid species richness and abundance on $200 \mathrm{~m}$ transects. In contrast, biological diversity of the substratum $\left(\mathrm{H}^{\prime}\right)$ was highly correlated with overall fish species richness. Numbers of holes of 3 sizes taken together accounted for $77 \%$ of the variance in overall fish abundance on the $200 \mathrm{~m}$ transects. None of the measures of structural complexity were significantly correlated with species richness or abundance of small, strongly siteattached fish. Live coral cover was not significantly correlated with species richness or abundance of fish from any family (except for a weak correlation with abundance of obligate corallivorous chaetodontids).
\end{abstract}

\section{INTRODUCTION}

Coral reefs support very diverse fish communities, ranging from around 500 to 700 species altogether on the reefs in the Caribbean and central Pacific, to $3000+$ on reefs around the Philippines and Indonesia (Goldman \& Talbot 1976, Sale 1980). The extent to which components of within-habitat and between-habitat diversity contribute to differences in the richness of fish communities between different areas is unclear. Some studies suggest that comparable habitats support more species in areas with larger species pools than in those with small species pools (Smith 1978, Walsh 1985), whilst others suggest that within-habitat diversity is similar between areas with very different sized species pools (Sale 1980, Talbot \& Gilbert 1981). This study looks at the factors which affect within-habitat diversity in fish communities from the central Red Sea.

Several studies have examined relationships between various substratum variables and the species

\footnotetext{
- Addressee for correspondence
}

richness and abundance of resident fish communities on coral reefs (Risk 1972, Gladfelter \& Gladfelter 1978, Luckhurst \& Luckhurst 1978, Carpenter et al. 1981, McManus et al. 1981, Bell \& Galzin 1984, Sano et al. 1984). Several of these studies found positive correlations between substratum structural complexity and fish species richness or diversity (Risk 1972, Luckhurst \& Luckhurst 1978, Carpenter et al. 1981). These have restricted attention to small, site-attached species with rather limited ranges of movement.

Correlations between structural complexity and fish abundance have been less consistent. Carpenter et al. (1981) found a strong positive correlation of fish biomass but not abundance with substratum complexity, whilst Luckhurst \& Luckhurst (1978) found that fish abundance and substratum complexity were strongly correlated at only one of 2 sites studied. In Risk's (1972) study, fish abundance and substratum complexity were not significantly correlated (Kendall's tau $=-0.10$, computed from data in Appendices A and B of Risk 1972). Gladfelter \& Gladfelter (1978) suggested that, qualitatively, fish abundance on patch reefs increased 
with increasing structural complexity. However, no quantitative data were obtained to support this claim.

There has also been little consistency between studies concerning the influence of live coral cover. Some studies have found positive correlations between the amount of live coral cover and fish diversity and abundance (Carpenter et al. 1981, Reese 1981, Bell \& Galzin 1984, Bouchon-Navaro et al. 1985) whilst others have found little or no correlation (Luckhurst \& Luckhurst 1978, McManus et al. 1981, Bell et al. 1985).

In this study we assess the influence of several substratum variables, particularly habitat structural complexity and live coral cover, on species richness and abundance of fish from several families. We also compare the influence of these variables at 2 different scales of sampling in order to assess whether the correlations between fish diversity and substratum structural complexity found previously are restricted to strongly site-attached species or whether they are found also with more mobile species. Our findings indicate that fish species richness is only weakly correlated with habitat structural complexity and that no single substratum variable we measured is a good correlate of overall fish abundance. Amount of live coral cover appears to have little influence on species richness or abundance of fishes from any family.

\section{METHODS}

Fish counts. Species of fish from 5 families were counted along four $200 \mathrm{~m}$ long, $5 \mathrm{~m}$ wide transects laid along the fore-reef at 4 sites on the Saudi Arabian Red Sea coast (Fig. 1). Pomacentridae (damselfishes), Lab-

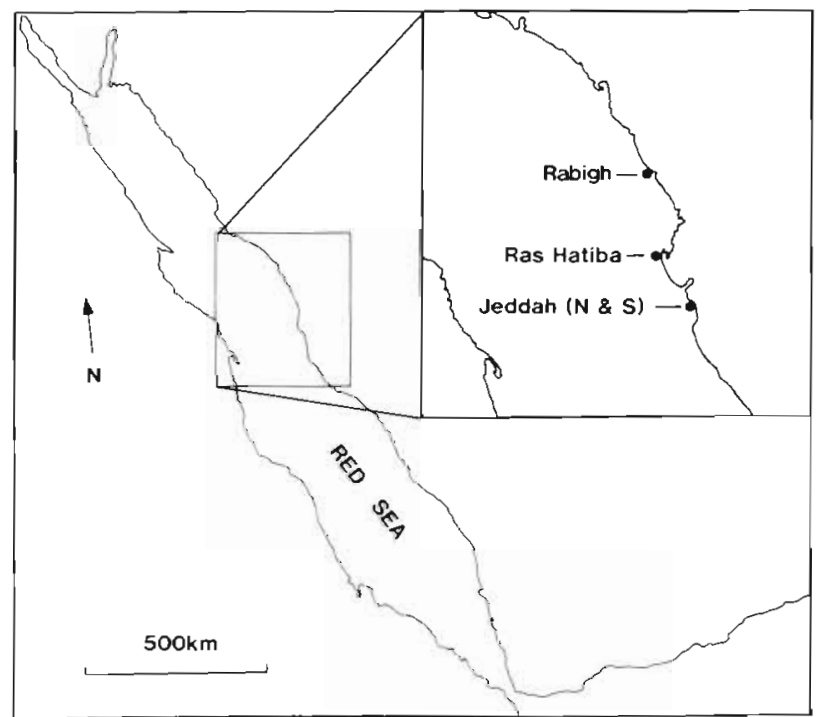

Fig. 1. Locations of the 4 study sites on the Saudi Arabian Red Sea coast ridae (wrasse), Chaetodontidae (butterflyfishes) and Scaridae (parrotfishes) were counted at all 4 sites and Acanthuridae (surgeonfishes) at 3 . The transects were laid parallel to the reef crest at depths of $1 \mathrm{~m}(1 \mathrm{~m}$ terrace), $1.5 \mathrm{~m}$ (reef-edge), $6 \mathrm{~m}$ (reef-face) and $12 \mathrm{~m}$ (fore-reef slope) (Fig. 2). Transect width was estimated visually. Species from different families were counted on separate swims along each transect.

Additionally, in order to count fishes very closely associated with the substratum, which could not be accurately or easily counted over $200 \mathrm{~m}$ transects, five $10 \mathrm{~m}$ long, $2 \mathrm{~m}$ wide transects were laid parallel to the reef-crest on the fore-reef at each of 3 sites: Jeddah south, Jeddah north and Ras Hatiba. These transects were situated at the beginning of the $200 \mathrm{~m}$ fish transects and were at depths of $1 \mathrm{~m}(1 \mathrm{~m}$ terrace), $1.5 \mathrm{~m}$ and $3 \mathrm{~m}$ (reef-edge), $6 \mathrm{~m}$ (reef-face) and $10 \mathrm{~m}$ (fore-reef slope) (Fig. 2). Transects were marked using a $10 \mathrm{~m}$

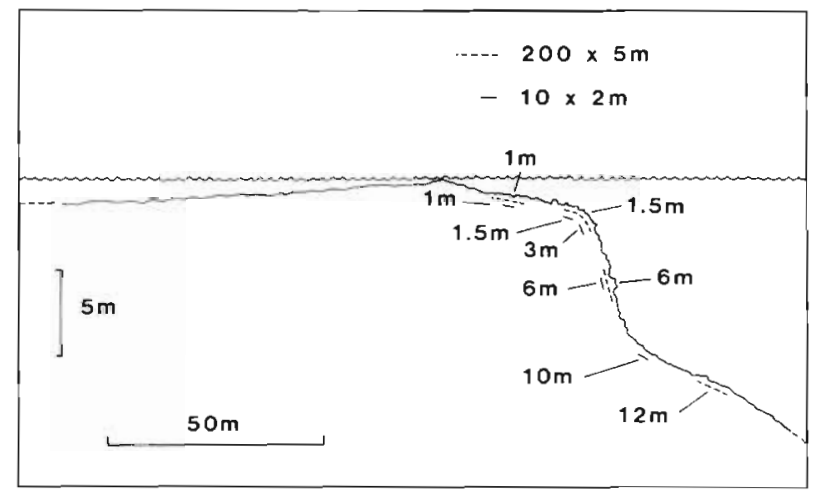

Fig. 2. Typical profile of the fringing reef at the 4 study sites showing the locations of the $200 \times 5 \mathrm{~m}$ and $10 \times 2 \mathrm{~m}$ fish count and stereophotographic transects. Transect widths are not shown to scale

tape measure. Small, 'resident' species were counted within a $1 \mathrm{~m}$ band either side of the tape (a total of $20 \mathrm{~m}^{2}$ ) by dividing the transect into ten $2 \times 1 \mathrm{~m} \mathrm{sec}$ tions (visually estimated). Each section was observed for $1 \mathrm{~min}$ and individuals of all species were recorded which spent more than $30 \mathrm{~s}$ within the section. Individuals whose movements overlapped more than one section were recorded only once. Counts from all ten $2 \mathrm{~m}^{2}$ sections from each transect were pooled prior to analysis.

Measurements on the substratum. Stereophotographs were taken at $1 \mathrm{~m}$ intervals along each of the $10 \mathrm{~m}$ transects used for counting resident fish. Although fish were not counted along $10 \mathrm{~m}$ transects at Rabigh, 5 transects were also laid at this site as above, and stereophotographs taken. Five photographs were chosen randomly from each transect and structural complexity measured from a $1 \mathrm{~m}^{2}$ area within each photograph. Structural complexity was estimated using 
Dahl's (1973) method. Dahl's surface index (S. I.) is the ratio of the actual surface area to that of a plane with the same dimensions (in this case $1 \mathrm{~m}^{2}$ ). The actual surface area within quadrats is measured by approximation. The scale of measurement is important since the smaller the units used, the greater will be the perceived surface area (Bradbury \& Reichelt 1983). The scale used in this study was appropriate to fish, the finest resolution being $1 \mathrm{~cm}$. This was also approximately the finest level of detail which could be resolved accurately from the stereophotographs. With Dahl's method, features of the reef are approximated as geometric shapes, each of which has a particular surface index. For example, a hemisphere has a surface index of 2. The surface indices of the 18 most common substrata found within the transects were estimated prior to analysis of the photographs. Any other substrata present within the quadrats had their surface indices calculated when they were encountered. The percentage cover of each substratum type within the quadrats was estimated visually from the stereophotographs using the transect line (tape measure) for scale. This has proved to be a relatively accurate method for measuring the composition of the substratum (Done 1981). The percent cover of each substratum type (expressed as a proportion) was then multiplied by its surface index and these summed to give an overall surface index for each quadrat. Hence, a flat quadrat with a $25 \%$ cover of hemispherical corals has a surface index of:

$$
\text { S. I. }=(0.25 \times 2)+(0.75 \times 1)=1.25
$$

For the purposes of comparison of fish community $(200 \times 5 \mathrm{~m}$ transects) and substratum characteristics, results from the 1.5 and $3 \mathrm{~m}$ depth phototransects were averaged since, due to the topography of the reefedge, both of these fall within the bounds of the $1.5 \mathrm{~m}$ fish transect (Fig. 2). The $10 \mathrm{~m}$ phototransect and the $12 \mathrm{~m}$ fish transect were situated in the same reef zone and were comparable. Phototransects and fish transects at 1 and $6 \mathrm{~m}$ respectively were directly comparable.

The percentage covers of different substrata on the $10 \mathrm{~m}$ transects were also measured from stereophotographs using the method of Loya (1978). The number of centimetres of the tape measure covering each substratum type, expressed as a percentage of the total transect length, gives an unbiased estimate of their cover. Hard and soft corals were classified into recognizable taxonomic units for this analysis.

As a second measure of the complexity of the substratum along the transects, the Shannon-Wiener index, $\mathrm{H}^{\prime}$, was calculated from the percentage cover data of different substratum types from each depth to give a measure of 'biological diversity' (Risk 1972).
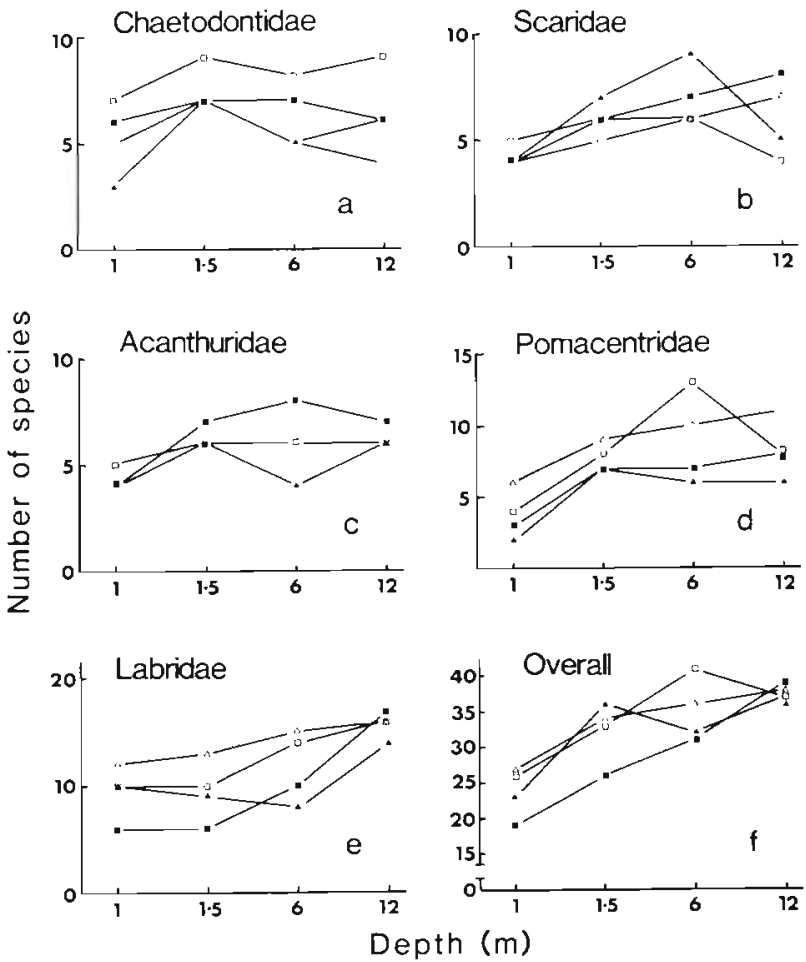

Fig. 3. Patterns of species richness of fish from the 5 families

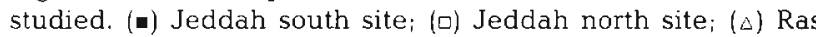
Hatiba; (4) Rabigh
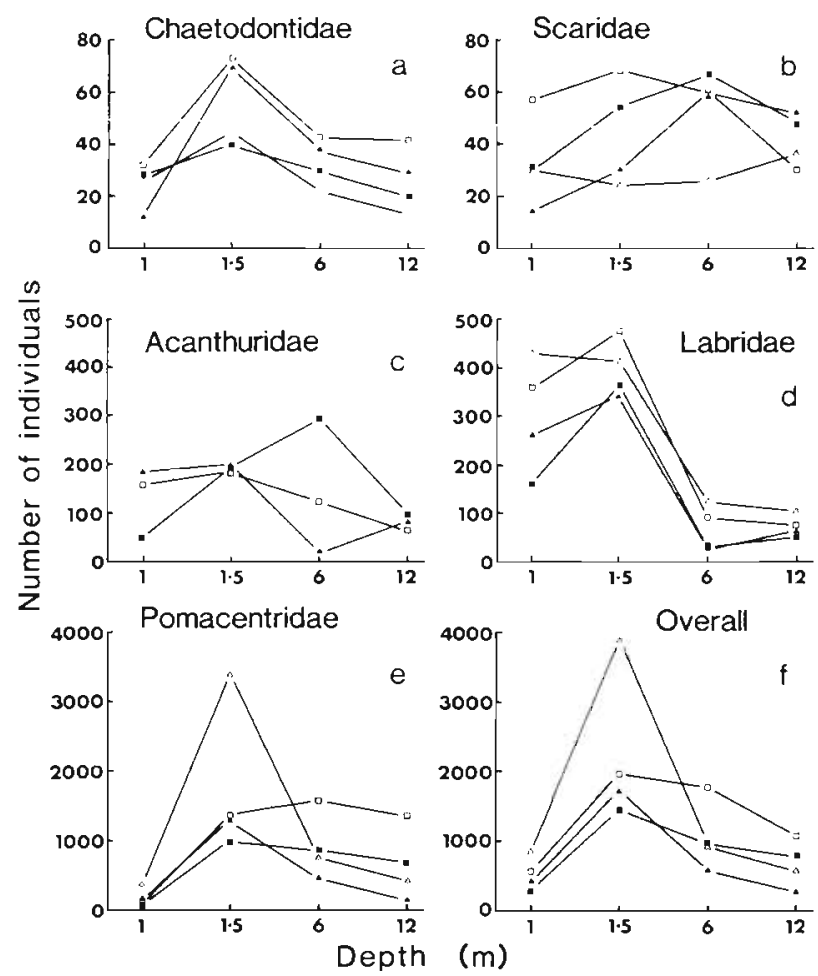

Fig. 4. Abundance distributions of fish from the 5 families studied. (a) Jeddah south site; (a) Jeddah north site; ( $\Delta$ ) Ras Hatiba; (^) Rabigh 
Holes are very important to small fish on coral reefs as refuges from predators. The numbers of holes were also counted within the same five $1 \mathrm{~m}^{2}$ quadrats on each transect from which surface indices were calculated. They were classified into the following size ranges (entrance diameter): 1 to 5,6 to 15,16 to 30,31 to 50 and $>50 \mathrm{~cm}$.

\section{RESULTS}

\section{Patterns of species richness and abundance}

Fig. 3 shows patterns of species richness over the reef at the 4 study sites for species from each family. There is considerable between-site variation in patterns of species richness for all families. The depth at which species richness is greatest varies between families. Overall, however, for the 5 families pooled, there is a general trend of increase in species richness with increasing depth.

Fig. 4 shows patterns of abundance for each family. For Chaetodontidae, Labridae and Pomacentridae, patterns of abundance distribution are relatively consistent between sites. In contrast, patterns of abundance for Scaridae and Acanthuridae vary widely between sites. The overall abundance distribution is very similar to that for pomacentrids with peak num-
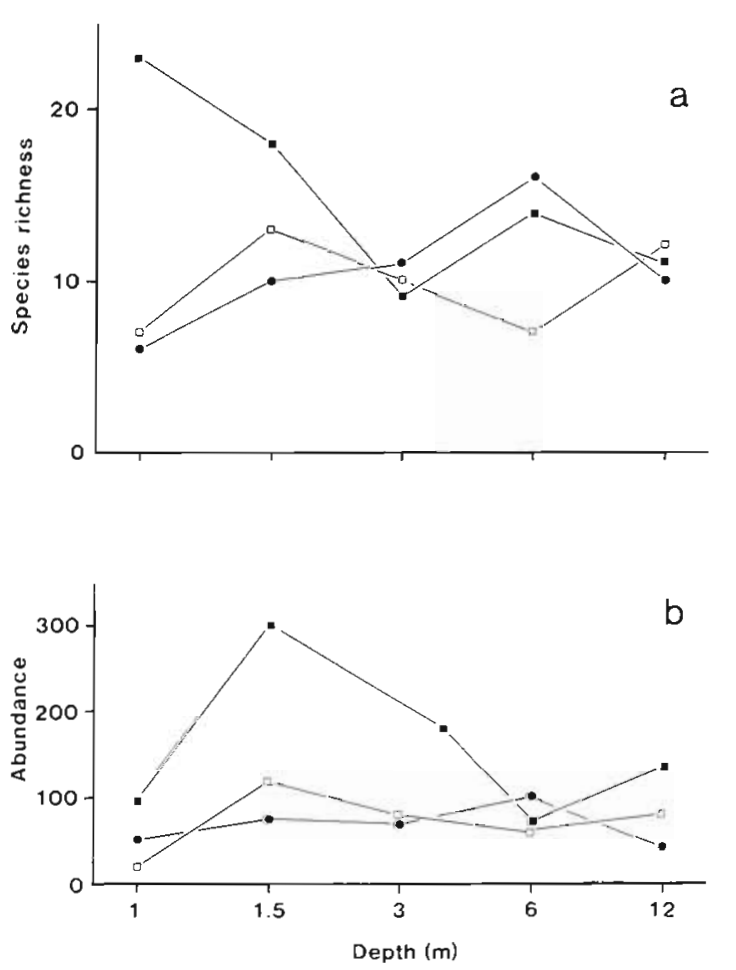

Fig. 5. (a) Species richness and (b) abundance of fishes counted on $10 \times 2 \mathrm{~m}$ transects. ( $\because$ ) Jeddah south; (•) Jeddah north; (-) Ras Hatiba bers being found at the reef-edge $(1.5 \mathrm{~m})$. This pattern is largely due to the influence of abundant planktivorous pomacentrids but is reinforced by similar patterns in the Labridae and Chaetodontidae.

There is a great deal of between-site variability in both abundance and species richness of fishes on the $10 \times 2 \mathrm{~m}$ transects, and no consistency of patterns is apparent (Fig. 5).

\section{Structural complexity}

Patterns of structural complexity (S. I.) were very similar between all sites although some had a generally higher level of complexity than others (Fig. 6a). At all
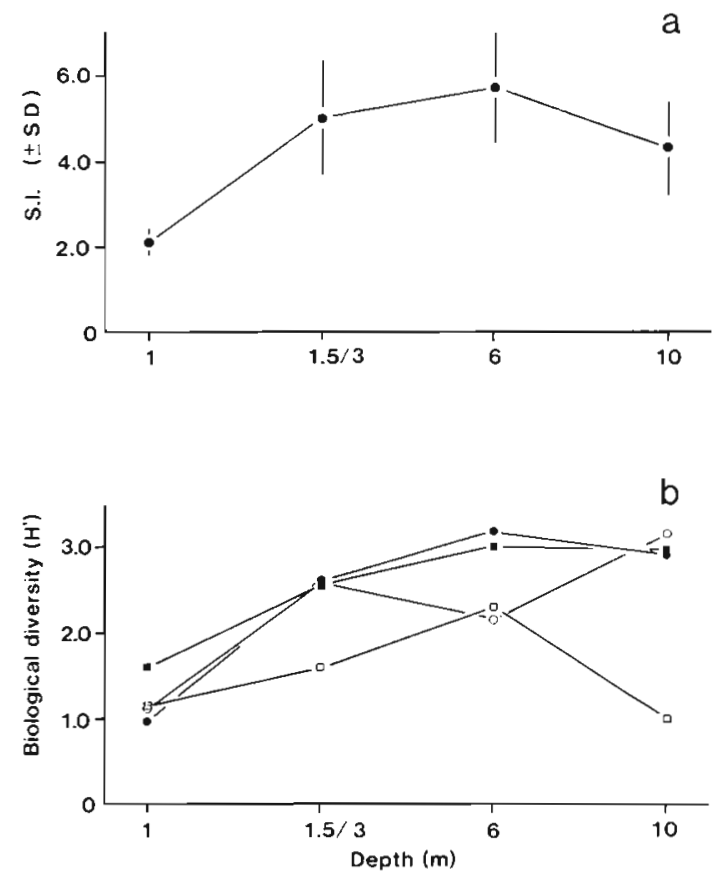

Fig. 6. (a) Pattern of average structural complexity (surface index) and (b) of biological diversity of the substratum over the reef from the 4 study sites. Symbols in (b): (a) Jeddah south site, (•) Jeddah north site, (-) Ras Hatiba and (o) Rabigh. In both cases the figures given for $1.5 \mathrm{~m}$ depth are derived from pooled values from transects at depths of 1.5 and $3 \mathrm{~m}$

sites surface index was highest between 3 and $6 \mathrm{~m}$ deep. Biological diversity of the substratum was much more variable between sites (Fig.6b).

The depth distributions of holes of different sizes are shown in Fig. 7. This is a more direct measure of the availability of shelter to fish than either surface index or biological diversity. Again, there is considerable variability between sites. However, in general the largest numbers of holes of all sizes were found between 1.5 and $6 \mathrm{~m}$ deep. 



Fig. 7. Depth distribution of holes of different sizes at the 4 sites studied

Relationships between substratum variables and the fish community

Kendall's rank correlation coefficients were calculated in order to assess the relationships between substratum variables and counts of fish from the $200 \times 5 \mathrm{~m}$ and $10 \times 2 \mathrm{~m}$ transects. Because a large number of these were calculated, a significance level of $p<0.01$ was used to reduce the chances of making a Type I error (accepting that 2 variables are significantly correlated when they are not).

Structural complexity. Structural complexity of the substratum (as measured by surface index) is significantly correlated only with pomacentrid abundance $(\operatorname{tau}=0.52)$ and species richness (tau $=0.48)$. However, both of these correlations are weak. S. I. does not correlate significantly with either abundance or species richness of fishes on the $10 \times 2 \mathrm{~m}$ transects.

Biological diversity. In contrast to Risk's (1972) findings that biological diversity of the substratum was a poor predictor of species diversity, in this study overall fish species richness (on $200 \times 5 \mathrm{~m}$ transects) was highly positively correlated with this measure (tau $=$ 0.81). However, biological diversity was not significantly correlated with overall fish abundance
( $200 \times 5 \mathrm{~m}$ transects), nor with abundance or species richness of fish on the $10 \times 2 \mathrm{~m}$ transects.

Depth. Depth alone is also a relatively good predictor of overall species richness (tau $=0.68$ ) and so a stepwise multiple regression was performed to investigate the relative effects of depth, biological diversity and surface index. The addition of neither depth nor surface index significantly increased the proportion of the variance in species richness explained by biological diversity alone $\left(r^{2}=0.90\right)$.

Numbers of holes. The availability of shelter, as measured by numbers of holes, was not correlated with overall species richness or abundance on either $200 \times 5 \mathrm{~m}$ or $10 \times 2 \mathrm{~m}$ transects. However, numbers of holes of 16 to $30 \mathrm{~cm}$ and 31 to $50 \mathrm{~cm}$ were correlated with scarid species richness (tau $=0.51$ and 0.50 , respectively), but not abundance, and holes of 6 to $15 \mathrm{~cm}$ and $>50 \mathrm{~cm}$ were correlated with pomacentrid abundance $(\mathrm{tau}=0.56$ and 0.54 , respectively), but not with species richness. Numbers of holes $>50 \mathrm{~cm}$ diameter were also correlated with chaetodontid abundance $(\operatorname{tau}=0.56$ ).

Since none of the substratum variables measured in this study individually accounted for much of the variance in overall fish abundance (on $200 \times 5 \mathrm{~m}$ transects), a stepwise multiple regression of all substratum variables on total fish abundance was performed (Table 1). Individually, the numbers of holes $>50 \mathrm{~cm}$

Table 1. Stepwise multiple regression analysis of substrate variables on overall fish abundance

\begin{tabular}{|lc|}
\hline Variable & $\begin{array}{r}\text { \% Variance } \\
\text { explained }\end{array}$ \\
\hline No. of holes $>50 \mathrm{~cm}$ : alone & $32.2^{\circ}$ \\
No. of holes 31 to $50 \mathrm{~cm}$ : additional & $19.2^{\circ}$ \\
No of holes 6 to $15 \mathrm{~cm}$ : additional & Total $\frac{25.4^{*}}{76.8 \%}$ \\
& \\
\hline$p<0.05^{*} \cdots p<0.01$ & \\
\hline
\end{tabular}

diameter explain the largest amount of the variance in abundance, but addition of numbers of holes of 31 to $50 \mathrm{~cm}$ and 6 to $15 \mathrm{~cm}$ significantly improve the correlation. Overall, these 3 variables account for $77 \%$ of the variance in total fish abundance.

Live coral cover. The percentage cover of live scleractinian corals did not correlate significantly with abundance or species richness of any of the fish families in this study, nor with overall abundance or species richness on the $200 \times 5 \mathrm{~m}$ or $10 \times 2 \mathrm{~m}$ transects. Several studies have suggested that chaetodontid abundance is related to the abundance of live corals (Reese 1977, 1981, Bouchon-Navaro et al. 1985). 
Restricting attention only to obligate corallivores (Chaetodon austriacus, C. larvatus, and C. trifascialis; Harmelin-Vivien \& Bouchon-Navaro 1981), the pooled abundance of the 3 species correlates weakly with coral cover (tau $=0.39, p<0.05$ ), although when the species are treated individually, correlations are nonsignificant.

Other substratum variables. Of the other substratum variables measured (soft coral cover, filamentous algal cover and coralline algal cover) soft coral cover was significantly positively correlated with labrid species richness (tau $=0.50$ ), pomacentrid species richness (tau $=0.57$ ) and overall species richness (tau $=0.59$ ). However, the effect of this variable is confounded with depth (tau $=0.59$ ) and biological diversity (tau $=0.74)$. Filamentous algal cover and coralline algal cover were not significantly correlated with abundance or species richness of any family or with overall abundance or richness of fishes on $200 \times 5 \mathrm{~m}$ or $10 \times 2 \mathrm{~m}$ transects.

\section{DISCUSSION}

Three previous studies, concentrating on small, strongly site-attached species, have found strong quantitative relationships between species richness or diversity of fishes and measures of structural complexity on coral reefs (Risk 1972, Luckhurst \& Luckhurst 1978, Carpenter et al. 1981). However, in this study, structural complexity was found to be only very weakly correlated with overall fish species richness from the $200 \times 5$ m transects ( $\mathrm{tau}=0.39, \mathrm{p}<0.05$ ) and not at all with counts of resident fish from the $10 \times 2 \mathrm{~m}$ transects. Depth alone was a much better predictor of species richness than surface index. However, biological diversity of the substratum was highly positively correlated with overall fish species richness from the $200 \times 5 \mathrm{~m}$ transects. This is exactly the opposite pattern to that found by Risk (1972) in the Virgin Islands where biological diversity was not significantly correlated with fish diversity ( $\mathrm{r}=-0.16$ ) but structural complexity was $(r=0.62)$. Direct measurements of the availability of shelter to fish (numbers of holes) were found not to be correlated significantly with fish species richness.

Increases in fish species richness with habitat complexity are only partially due to increases in the overall abundance of fish. In only 3 of the 5 families of fish studied was species richness significantly positively correlated with abundance, and patterns of abundance distribution over the reef are quite different from those of species richness (Fig. $3 \& 4$ ), both within families and overall. In this study, no single substratum variable was found to be a good predictor of the overall abundance of fish. However, numbers of holes of 3 sizes, taken together, account for $77 \%$ of the variance in fish abun- dance over the reef, underlining the importance of shelter to reef fishes.

The influence of particular substratum characteristics was not the same on fish from different families (and will not be on species within families although this level of detail is not considered in this study). Those species which are small and remain close to the substratum might be expected to be influenced most by local substratum characteristics. Most pomacentrid species are strongly site-attached, having only small territories or home-ranges (Sale 1974, 1978, Fricke 1975). Within only this family was surface index significantly positively correlated with abundance and species richness. Species within the Chaetodontidae range from having small home-ranges and territories to quite extensive ones. However, chaetodontid abundance is not significantly positively correlated with any measure of substratum complexity except numbers of holes $>50 \mathrm{~cm}$ diameter (tau $=0.56$ ). Labrids, acanthurids and scarids also have a very wide range of home-range and territory sizes and none of the measures of complexity correlate significantly with either species richness or abundance (except for scarid species richness which correlates significantly with the numbers of holes of 16 to $30 \mathrm{~cm}$ and 31 to $50 \mathrm{~cm}$ diameter). These data thus qualitatively seem to support the view that the composition of the substratum has a stronger local influence on resident communities of small, strongly site-attached species than on wider ranging species. However, data from the $10 \times 2 \mathrm{~m}$ transects, in which only such species were recorded, do not. On these transects neither abundance nor species richness were significantly correlated with any substratum variable. Why such species appear not to be strongly influenced by the substratum at these sites in the Red Sea but were at sites in the Caribbean and Pacific is not known.

The amount of live coral cover was found to have little influence on the abundance or species richness of fishes from any family. Even when attention was restricted only to obligate corallivorous chaetodontids, only a very weak association was found. This finding contrasts with that of Bell \& Galzin (1984) who concluded that percentage live coral cover had a strong positive influence on both total species richness and abundance of resident fishes. Similarly, Bouchon-Navaro et al. (1985) were able to demonstrate significant correlations between the density of coral feeding chaetodontids and amount of live coral cover at a site in Moorea, French Polynesia. However, in a large scale study, Bell et al. (1985) found that coral cover and chaetodontid abundance and diversity were only weakly correlated with the amount of live coral but noted that rich and abundant assemblages were only found at sites rich in coral. Sano et al. (1984), in a series 
of experiments using living and dead branching corals, reported that, overall, dead colonies support fewer individuals and species of resident fishes than do live colonies.

Reese $(1977,1981)$ suggested that the abundance of obligate corallivorous chaetodontid species be used as an indicator of the 'health' of coral reefs, healthy reefs being those with large amounts of live coral cover. He developed the argument that coral feeding species would respond to changes in the coral community before direct measurements on this community would show that a reef had been damaged. However, evidence that abundance of coral feeding chaetodontids is strongly influenced by the amount of coral cover is equivocal. In addition, many healthy and undisturbed reefs have naturally low levels of coral cover (e.g. Sheppard 1985). The present study suggests that abundance of corallivorous chaetodontids is a poor indicator of live coral cover (and hence reef health) and that high levels of between-site variability in abundance would mask variations due to changes in the coral community within sites.

The distribution of fishes on coral reefs is not influenced only by the composition of the substratum. In particular, this study has ignored the effects of interspecific interactions on fish distribution. For example, territorial herbivorous acanthurids and pomacentrids can have an important influence on the distribution of other herbivorous species, particularly scarids (Robertson et al. 1979, Roberts 1985, Robertson \& Gaines 1986; buit see Choat \& Bellwood 1985). The territoria! activities of these species also affect the composition of the substratum, altering patterns of live coral cover (Dart 1972, Neudecker 1979, Sammarco \& Carleton 1981) and, as a consequence, habitat structural complexity. Hence it is impossible to assess the effects of different substratum variables on fish abundance and species richness in isolation without experimentation, since the substratum is not independent of the fish community. It is probably largely because of this interdependence that, in this study, most of the substratum variables measured were found to be poor correlates of fish species richness and abundance either within families or at the community level. This is also the probable reason for the large discrepancies between the results of similar studies from different regions.

Acknowledgements. We thank Tim Wrathall, Alec Dawson Shepherd and Rick Moore for undertaking some of the fish counts used in this study, and Romilly Locker for taking the stereophotographs of transects. This research was supported by funds from the International Union for the Conservation of Nature and Natural Resources (IUCN), the Meteorology and Environmental Protection Administration of Saudi Arabia (MEPA), and a Science and Engineering Research Council (UK) studentship to C. R.

\section{LITERATURE CITED}

Bell, J. D., Galzin, R. (1984). Influence of live coral cover on coral reef fish communities. Mar Ecol. Prog. Ser. 15: 265-274

Bell, J. D., Harmelin-Vivien, M., Galzin, R. (1985). Large scale spatial variation in the abundance of butterflyfishes (Chaetodontidae) on Polynesian reefs. Proc. Fifth Int. Coral Reef Congress, Tahiti 5: 421-426

Bouchon-Navaro, Y., Bouchon, C., Harmelin-Vivien, M. (1985). Impact of coral degradation on a chaetodontid fish assemblage (Moorea, French Polynesia). Proc. Fifth Int. Coral Reef Congr., Tahiti 5: 427-432

Bradbury, R. H., Reichelt, R. E. (1983). Fractal dimension of a coral reef at ecological scales. Mar. Ecol. Prog. Ser. 10; $169-171$

Carpenter, K. E., Miclat, R. I., Albaladejo, V. D., Corpuz, V. T. (1981). The influence of substrate structure on the local abundance and diversity of Philippine reef fishes. Proc. Fourth Int. Coral Reef Symp., Manila 2: 497-502

Choat, J. H., Bellwood, D. R. (1985). Interactions amongst herbivorous fishes on a coral reef: influence of spatial variation. Mar. Biol. 89: 221-234

Dahl, A. L. (1973). Surface area in ecological analysis: quantification of benthic coral-reef algae. Mar. Biol. 23: 239-249

Dart, J. K. G. (1972). Echinoids, algal lawn and coral recolonisation. Nature, Lond. 239: 50-51

Done, T. J. (1981). Photogrammetry in coral ecology: a technique for the study of change in coral communities. Proc. Fourth Int. Coral Reef Symp., Manila 2: 315-320

Fricke, H. W. (1975). Evolution of social systems through site attachment in fish. Z. Tierpsychol. 39: 206-210

Gladfelter, W. B., Gladfelter, E. H. (1978). Fish community structure as a function of habitat structure on West Indian patch reefs. Rev. Biol. Trop. 26 (Suppl. 1): 65-84

Goldman, B., Talbot, F. H. (1976). Aspects of the ecology of coral reef fishes. In: Jones, O. A., Endean, R. (ed.) Biology and geology of cordil teefs. Vúl.3, Biolugy 2. Academic Press, New York, p. 125-154

Harmelin-Vivien, M. L., Bouchon-Navaro, Y. (1982). Trophic relationships among chaetodontid fishes in the Gulf of Aqaba (Red Sea). Proc. Fourth Int. Coral Reef Symp., Manila 2: $537-544$

Loya, Y. (1978). Plotless and transect methods. In: Stoddart, D. R., Johannes, R. E. (ed.) Coral reefs: research methods. UNESCO, Paris, p. 197-218

Luckhurst, B. E., Luckhurst, K. (1978). Analysis of the influence of substrate variables on coral reef fish communities. Mar. Biol. 49: 317-323

McManus, J. W., Miclat, R. I., Palaganas, V. P. (1981). Coral and fish community structure of Sombrero Island, Batangas, Philippines. Proc. Fourth Int. Coral Reef Symp., Manila 2: $271-280$

Neudecker, S. (1979). Effects of grazing and browsing fishes on the zonation of corals in Guam. Ecology 60: 666-672

Reese, E. S. (1977). Coevolution of corals and coral feeding fishes of the family Chaetodontidae. Proc. Third Int. Coral Reef Symp., Miami 1: 267-274

Reese, E. S. (1981). Predation on coral by fishes of the family Chaetodontidae: implications for conservation and management of coral reef ecosystems. Bull. mar. Sci. 31: $594-604$

Risk, M. J. (1972). Fish diversity on a coral reef in the Virgin Islands. Atoll Res. Bull. 193: 1-6

Roberts, C. M. (1985). Resource sharing in territorial herbivorous reef fishes. Proc. Fifth Int. Coral Reef Congress, Tahiti 4: 17-22 
Robertson, D. R., Polunin, N. V C., Leighton, K. (1979). The behavioural ecology of three Indian Ocean surgeonfishes (Acanthurus lineatus, A. leucosternon and Zebrasoma scopas): their feeding strategies and social and mating systems. Environ Biol. Fish. 4: 125-170

Robertson, D. R., Gaines, S. D. (1986). Interference competition structures habitat use in a local assemblage of coral reef surgeonfishes. Ecology 67: 1372-1383

Sale, P. F. (1974). Mechanisms of coexistence in a guild of territorial reef fishes at Heron Island. Proc. Second Int. Coral Reef Symp., Brisbane 1: 193-206

Sale, P. F. (1978). Reef fishes and other vertebrates: a comparison of social structures. In: Reese, E. S., Lighter, F. J (ed.) Contrasts in behaviour. John Wiley, New York, p. 313-346

Sale, P. F. (1980). The ecology of fishes on coral reefs. Oceanogr. mar. Biol. A. Rev. 18: 367-421

Sammarco, P. W. Carleton, J. H. (1981). Damselfish territo- riality and coral community structure: reduced grazing coral recruitment, and effects on coral spat. Proc. Fourth Int. Coral Reef Symp., Manila 2: 525-535

Sano, M., Shimizu, M., Nose, Y. (1984). Changes in the structure of coral reef fish communities by destruction of hermatypic corals: observational and experimental views Pacif. Sci. 38: 51-79

Sheppard, C. R. C. (1985). Reefs and coral assemblages of Saudi Arabia 2. Fringing reefs in the southern region, Jeddah to Jizan. Fauna of Saudi Arabia 7: 37-58

Smith, C. L. (1978). Coral reef fish communities: a compromise view. Environ. Biol. Fish. 3: 109-128

Talbot, F. H., Gilbert, A. J. (1981). A comparison of quantitative samples of coral reef fishes latitudinally and longitudinally. Proc. Fourth Int. Coral Reef Symp., Manila 2: 485-490

Walsh, W. J. (1985). Reef fish community dynamics on small artificial reefs: the influence of isolation, habitat structure and biogeography. Bull. mar. Sci. 36: 357-376

This article was submitted to the editor; it was accepted for printing on September 9, 1987 